COSTING:Journal of Economic, Business and Accounting Volume 3 Nomor 1, Desember 2019

e-ISSN : 2597-5234

IPMEKpe

\title{
ANALISIS DAMPAK EKONOMI PELAKSANAAN JALAN SIMPANG RUKIS - TANJUNG KEMUNING PROVINSI BENGKULU
}

\author{
ECONOMIC IMPACT ANALYSIS OF IMPLEMENTATION OF ROAD \\ SIMPANG RUKIS - TANJUNG KEMUNING BENGKULU PROVINCE
}

\author{
Azuwandri \\ Sekolah Tinggi Ilmu Administrasi Bengkulu (STIA) \\ azuwandri24@gmail.com
}

\begin{abstract}
Public transportation is transportation that is needed by most urban communities, a city cannot survive without public transportation. The main objective of this study is to determine the reduction of road user costs and financial analysis of NPV (Net Present Value) and BCR (Benefit Cost Ratio). The research method used is descriptive which is used to analyze the impact of time and cost savings, the method used is a descriptive statistical method, NPV and BCR Financial Impact Testing and investment feasibility sensitivity analysis. The results showed the cost efficiency of road users was Rp. $600,001.24$ and increase travel speed to $50 \mathrm{~km} /$ hour. Vehicle Operating Costs (BOK) consist of fixed costs and operational cost components. Efficiency of expansion of vehicle operations to Rp. 1,921,187. From the financial analysis the implementation path of Simpang Rukis - Tanjung Kemuning is economically feasible. This is the result of a performance with NPV of Rp. 1,921,187, -> 0 and BCR 1.18> 1. Sensitivity analysis is shown when costs increase by 15\%, NPV is Rp. 1,921,187 and BCR decreased to 1.03. When the benefits decrease by $15 \%$, the NPV drops to Rp. 1,306,921,187 and BCR up to 1,004. When costs increase by $15 \%$ and benefits decrease by 15\%, the NPV drops to Rp. 1,306,921,187 and BCR to 0.87 and the road is economically unfeasible. Conclusion, with the construction and maintenance of roads and bridges at Simpang Rukis - Tanjung Kemuning, it is hoped that the pace of transportation is efficient and economical so that it can accelerate the economy of Bengkulu province, especially the people of Simpang Rukis - Tanjung Kemuning.
\end{abstract}

Keywords: Economic Feasibility, NPV, BCR, Sensitivity Analysis

\begin{abstract}
ABSTRAK
Angkutan umum adalah transportasi yang sangat dibutuhkan oleh sebagian besar masyarakat perkotaan, sebuah kota tidak dapat bertahan tanpa transportasi umum. Tujuan utama dari penelitian ini adalah untuk menentukan pengurangan biaya pengguna jalan dan analisis finansial NPV (Net Present Value) dan BCR (Benefit Cost Ratio). Metode penelitian yang digunakan adalah deskriptif yang digunakan untuk menganalisis tentang dampaknya penghematan waktu dan biaya, metode yang digunakan adalah metode statistika diskriftif, Pengujian dampak Finansial NPV dan BCR dan analisis sensitivitas kelayakan investasi. Hasil penelitian menunjukkan efisiensi biaya pengguna jalan adalah Rp. 600.001,24 dan meningkatkan kecepatan perjalanan menjadi $50 \mathrm{~km} /$ jam. Biaya Operasional Kendaraan (BOK) terdiri atas
\end{abstract}


biaya tetap dan komponen biaya operasional. Efisiensi ekspansi pengoperasian kendaraan menjadi Rp. 1.921.187, -. Dari analisis finansial jalan implementasi Simpang Rukis - Tanjung Kemuning layak secara ekonomi. Ini adalah hasil pertunjukan dengan NPV Rp. 1.921.187, -> 0 dan BCR 1.18> 1. Analisis sensitivitas ditunjukkan ketika biaya meningkat 15\%, NPV adalah Rp. 1.921.187 dan BCR menurun menjadi 1.03. Ketika manfaat menurun 15\%, NPV turun menjadi Rp. 1.306.921.187, - dan BCR hingga 1.004. Ketika biaya meningkat $15 \%$ dan manfaat menurun 15\%, NPV turun menjadi Rp. 1.306.921.187, - dan BCR ke 0,87 dan jalan secara ekonomi tidak layak. Simpulan, dengan adanya pembangunan dan pemeliharaan jalan dan jembatan Simpang Rukis - Tanjung Kemuning diharapkan laju transportasi yang efisien dan ekonomis sehingga dapat mempercepat perekonomian propinsi Bengkulu khususnya masyarakat Simpang Rukis - Tanjung Kemuning.

Kata Kunci: Economic Feasibility, NPV, BCR, Sensitivity Analysis

\section{PENDAHULUAN}

Dampak suatu aktivitas pembangunan terhadap perekonomian daerah bisa diukur melalui penciptaan lapangan kerja, peningkatan pendapatan per kapita, pertumbuhan dan peningkatan daya tarik investasi, produktivitas investasi, dan berbagai bentuk manfaat lainnya.

Sedangkan beberapa manfaat yang berpotensi muncul akibat dari perkembangan sektor transportasi adalah: 1) perubahan biaya relatif dari sarana transportasi tertentu terhadap sarana transportasi lainnya, 2) peningkatan pendapatan perkapita masyarakat, 3) peningkatan ketersediaan sarana transportasi, 4) peningkatan kualitas perjalanan (kecepatan, kenyamanan, kepercayaan) yang dihasilkan dari peningkatan kualitas sarana maupun teknologi infrastrukturnya, 5) pengaruh pada tata guna lahan akibat migrasi antar daerah dan perubahan pola pemukiman, 6) peningkatan aktivitas ekonomi, 7) perubahan pola dan struktur konsumsi masyarakat, 8) perubahan demografis (struktur usia dan gender), 9) perubahan perilaku operasional dunia usaha setempat.

Studi kelayakan proyek dilakukan dengan analisa yang disebut analisa manfaat dan biaya (Cost and Benefit Analysis) termasuk didalamya semua manfaat dan biaya sosial (Social Cost and Social Benefit). Dengan demikian, pada umumnya suatu studi kelayakan proyek akan menyangkut pada manfaat ekonomis proyek tersebut bagi proyek itu sendiri (sering juga disebut sebagai manfaat financial). Yang berarti apakah proyek itu dipandang cukup menguntungkan apabila dibandingkan dengan risiko proyek itu.

Manfaat ekonomis proyek itu bagi negara tempat proyek dilaksanakan (sering juga disebut sebagai manfaat ekonomi nasional), yang menunjukkan manfaat proyek tersebut bagi ekonomi makro suatu negara.

Sepanjang 5 tahun ini Kementerian Pekerjaan Umum dan Perumahan Rakyat telah menganggarkan dana untuk penyelenggaraan kegiatan pemeliharaan rutin dan peningkatan kapasitas jalan pada jalur Simpang Rukis - Tanjung (lintas barat) yang termasuk dalam ruas jalan nasional sebesar Rp 265,54 Miliyar

Dalam suatu negara yang sedang membangun selalu dibutuhkan kegiatan-kegiatan pembangunan seperti proyek yang merupakan unit 
operasional pembangunan yang paling kecil (Pudjosumarto, 1998). Dengan adanya proyek tersebut, pendapatan suatu negara diharapkan dapat meningkat, disamping investasi kegiatan proyek diharapkan dapat mengurangi perbedaan (disparitas) pendapatan masyarakat (Hensher et al., 1990)

Aspek Manajerial dan

Administratif (Husnan, 1999) menjelaskan bahwa aspek yang menyangkut kemampuan staf pelaksana untuk melaksanakan administrasi dalam aktivitas besar dan bagaimana hubungan antara administrasi proyek dengan lembaga lainya (misalnya pihak pemerintah) dapat terlihat dengan jelas. Sumber daya yang ada juga harus mampu mengelola proyek tersebut, dimulai dari tahapan perencanaan, pelaksanaan, operasional maupun pemeliharaan. Kajian dilakukan secara menyeluruh terhadap staf proyek untuk melihat kemampuan mereka dalam menjalankan administrasi pengelolaan proyek dari awal sampai akhir. Sedangkan manajemen lebih ditekankan pada hal-hal yang berkaitan dengan : mekanisme kerja, gaya manajemen dan kualifikasi sumber daya manusia yang terlibat.

\section{METODE PENELITIAN}

Penelitian ini bersifat deskriptif, sehingga untuk data yang dihimpun akan dilakukan analisis pada masingmasing variabel yang dijadikan sebagai instrumen penelitian. Pemberian skoring atas variabel penelitian bersifat variatif, tergantung dari jenis data yang dihimpun. Terjadinya variasi dalam analisis dimaksud agar dalam mengungkapkan variabel yang diteliti secara rinci dan komperhensif mampu menjelaskan dan menjawab permasalahan yang diteliti. Untuk mengungkapkan persoalan pada ruas jalan Simpang Rukis - Tanjung Kemuning, dilakukan dengan mengidentifikasi sumber data yang ada dan jenis kendaraan sebagai pengguna jalan.

Data yang dipergunakan pada penelitian ini adalah data sekunder dari instansi/lembaga yang terkait antara lain : Badan Pusat Statistik (BPS) Provinsi Bengkulu, Kementerian Pekerjaan Umum dan Perumahan Rakyat, jenis data yang diambil adalah tahunan (time series) mulai dari tahun 2011 - 2015 yang bersifat kualitatif.

Data yang diambil dari instansi diantaranya; 1) bBdan Pusat Statistik (BPS) Provinsi Bengkulu, 2) Kementerian Pekerjaan Umum dan Perumahan Rakyat. Adapun data yang digunakan yaitu; 1) volume lalu lintas (Data Survei), 2) kondisi eksisting jalan, 3) kecepatan lalu lintas, 4) kapasitas Jalan, 4) dokumentasi, 5) harga dasar barang dan upah.

Dalam pengumpulan data sekunder digunakan metode dokumentasi. Cara ini dilakukan sebagai berikut; 1) melakukan inventarisasi sarana prasarana jalan, meliputi tingkat kerusakan jalan, jumlah lalulintas harian rata-rata (LHR), kondisi medan, tingkat kekasaran jalan dari Kementerian PUPera, 2) mengumpulkan berbagai referensi dari intansi terkait.

Untuk menganalisis tentang dampaknya penghematan waktu dan biaya, metode yang digunakan adalah metode statistika diskriftif yakni statistika yang menggunakan data pada suatu kelompok untuk menjelaskan atau menarik kesimpulan mengenai kelompok itu saja.

Dampak Finansial NPV dan BCR - Tujuan akhir yang ingin dicapai adalah secara akurat membandingkan kedua nilai, manakah yang lebih besar. Selanjutnya dari hasil pembandingan 
ini, pengambil keputusan dapat mempertimbangkan untuk melanjutkan suatu rencana atau tidak dari sebuah aktivitas, produk atau proyek, atau dalam konteks evaluasi atas sesuatu yang telah berjalan, adalah menentukan keberlanjutannya.

Salah satu metode untuk menganalisis manfaat dan biaya suatu proyek yaitu BCR (Benefit-Cost Ratio atau perbandingan manfaatbiaya). Metode BCR adalah suatu cara evaluasi suatu proyek dengan membandingkan nilai sekarang seluruh proyek diperoleh dari proyek tersebut dengan nilai sekarang seluruh biaya proyek tersebut. Cara menghitung BCR adalah sebagai berikut:

$$
N e t B / C=\frac{\sum_{i=1}^{n} N \overline{B_{i}}(+)}{\sum_{i=1}^{n} N \overline{B_{i}}(-)}
$$

Keterangan :

$\mathrm{NB}=$ Net Benefit (Benefit- Cost)

$\mathrm{C}=$ Biaya investasi + biaya operasional

$\mathrm{n}=$ tahun (Waktu)

$\mathrm{i}=$ Diskon Faktor

Jika $B / C \geq 1$ atau $B \geq C$ (proyek diterima) $\mathrm{B} / \mathrm{C}<1$ atau $\mathrm{B}<\mathrm{C}$ (proyek ditolak) $\mathrm{B} / \mathrm{C}=1$ atau $\mathrm{B}=\mathrm{C}$ (proyek dilaksanakan atau tidak dilaksanakan tidak berpengaruh). Apabila hasil yang diperoleh dari analisis manfaat dan biaya dalam suatu proyek adalah $\mathrm{C}>$ $\mathrm{B}$, yang berarti biaya yang dikeluarkan untuk membuat proyek lebih besar daripada manfaat yang diperoleh, maka proyek tersebut tidak layak untuk dijalankan atau dengan kata lain proyek ditolak.

Metode Net Present Value (NPV) dilakukan dengan cara mengurangi semua manfaat (benefit) dengan jumlah biaya (cost) total yang dibutuhkan setelah dikonversikan ke dalam nilai uang sekarang (present value). NPV = Benefit - Cost. Proyek dikatakan layak untuk dilaksanakan bila NPV $>0$

Pada dasarnya untuk menganalisis efisiensi suatu proyek langkah-langkah yang harus diambil adalah;

1. Menentukan semua manfaat dan biaya dari proyek yang akan dilaksanakan

2. Menghitung manfaat dan biaya dalam nilai uang

3. Menghitung masing-masing manfaat dan biaya dalam nilai uang sekrang.

Selanjutnya juga dilakukan analisis sensitivitas kelayakan investasi dengan mengubah nilai suatu variabel dan mengamati pengaruhnya terhadap kelayakan investasi. Dengan demikian dapat diketahui sensitivitas pengaruh variabel tersebut terhadap kelayakan investasi.

Analisis sensitivitas dalam penelitian ini dilakukan dengan mengasumsikan keadaan-keadaan terburuk yang mungkin terjadi seperti:

1. Biaya naik $15 \%$, manfaat tetap.

2. Biaya tetap, manfaat turun $15 \%$

3. Biaya naik $15 \%$, manfaat turun $15 \%$.

\section{HASIL DAN PEMBAHASAN Deskripsi Data}

Ruas Jalan Simpang Rukis Tanjung Kemuning yang ditangani dengan dana Loan WINRIP 8043-ID sepanjang 56,270 Kilometer terletak pada KM. 144+150 sampai dengan KM. 200+420 pada Lintas Barat Sumatera yang menghubungkan Provinsi Bengulu dengan Provinsi Lampung. 
Tabel 1 Tabel Data Kecepatan Rencana dan Waktu Tempuh sebelum Adanya Penanganan

\begin{tabular}{|c|c|c|c|c|c|c|c|}
\hline \multirow{3}{*}{$\begin{array}{c}\text { Jenis } \\
\text { Kendaraan }\end{array}$} & \multirow{2}{*}{$\begin{array}{l}\text { Kec. } \\
\text { Arus } \\
\text { Bebas } \\
\text { Dasar }\end{array}$} & \multirow{2}{*}{ FP } & \multirow{2}{*}{$\begin{array}{l}\text { Fvo + } \\
\text { FVw }\end{array}$} & \multicolumn{2}{|c|}{$\begin{array}{c}\text { Faktor } \\
\text { Penyesuaian }\end{array}$} & \multirow{2}{*}{$\begin{array}{c}\text { Kec. } \\
\text { Arus } \\
\text { Bebas }\end{array}$} & \multirow{2}{*}{$\begin{array}{c}\text { Waktu } \\
\text { Tempuh }\end{array}$} \\
\hline & & & & $\begin{array}{c}\text { Hamb } \\
\text { Samping }\end{array}$ & $\begin{array}{l}\text { Uk. } \\
\text { Kota }\end{array}$ & & \\
\hline & Fvo & FVw & $(\mathbf{K m} / \mathbf{j a m})$ & FFVsf & FFVrc & $\begin{array}{c}F V \\
(\mathrm{~km} / \mathrm{jam} \\
)\end{array}$ & (jam) \\
\hline Sedan & 61 & -3 & 58 & 0.87 & 0.91 & 45.92 & 1.23 \\
\hline Utiliti & 61 & -3 & 58 & 0.87 & 0.91 & 45.92 & 2.23 \\
\hline Bus Kecil & 52 & -3 & 49 & 0.87 & 0.91 & 38.79 & 1.45 \\
\hline Bus Besar & 62 & -3 & 59 & 0.87 & 0.91 & 46.71 & 1.20 \\
\hline Truk Ringan & 49 & -3 & 46 & 0.87 & 0.91 & 36.42 & 1.55 \\
\hline Truk Sedang & 49 & -3 & 46 & 0.87 & 0.91 & 36.42 & 1.55 \\
\hline Truk Berat & 49 & -3 & 46 & 0.87 & 0.91 & 36.42 & 1.55 \\
\hline
\end{tabular}

Tabel 1 menunjukkan waktu tempuh aktual dan kecepatan arus bebas sepanjang ruas Simpang Rukis Tanjung Kemuning sebelum adanya penanganan yaitu waktu tempuh 1,23 jam dan $45.92 \mathrm{~km} / \mathrm{jam}$ untuk kendaraan ringan. Untuk kendaraan berat waktu tempuh 1,45 jam dan kecepatan 38,79 $\mathrm{km} / \mathrm{jam}$, untuk bus ringan waktu tempuh $1,1.20$ jam dan kecepatan $46,71 \mathrm{~km} / \mathrm{jam}$ dan untuk kendaraan truk waktu tempuh 1,55 jam dan kecepatan $36,42 \mathrm{~km} / \mathrm{jam}$.

Tabel 2 Tabel Data Kecepatan Rencana dan Waktu Tempuh setelah Adanya Penanganan.

\begin{tabular}{|c|c|c|c|c|c|c|c|}
\hline \multirow{3}{*}{$\begin{array}{c}\text { Jenis } \\
\text { Kendaraan }\end{array}$} & \multirow{2}{*}{$\begin{array}{l}\text { Kec. } \\
\text { Arus } \\
\text { Bebas } \\
\text { Dasar }\end{array}$} & \multirow{2}{*}{ FP } & \multirow{2}{*}{$\begin{array}{l}\text { Fvo + } \\
\text { FVw }\end{array}$} & \multicolumn{2}{|c|}{$\begin{array}{c}\text { Faktor } \\
\text { Penyesuaian }\end{array}$} & \multirow{2}{*}{$\begin{array}{c}\text { Kec. } \\
\text { Arus } \\
\text { Bebas }\end{array}$} & \multirow{2}{*}{$\begin{array}{c}\text { Waktu } \\
\text { Tempuh }\end{array}$} \\
\hline & & & & $\begin{array}{c}\text { Hamb } \\
\text { Samping }\end{array}$ & $\begin{array}{c}\text { Uk. } \\
\text { Kota }\end{array}$ & & \\
\hline & Fvo & FVw & $(\mathbf{K m} / \mathbf{j a m})$ & FFVsf & FFVrc & $\begin{array}{c}\mathrm{FV} \\
(\mathrm{km} / \mathrm{jam} \\
)\end{array}$ & (jam) \\
\hline Sedan & 68 & 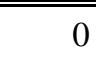 & 68 & 0.98 & 0.91 & 60.64 & 0.93 \\
\hline Utiliti & 68 & 0 & 68 & 0.98 & 0.91 & 60.64 & 0.93 \\
\hline Bus Kecil & 60 & 0 & 60 & 0.98 & 0.91 & 53.51 & 1.05 \\
\hline Bus Besar & 73 & 0 & 73 & 0.98 & 0.91 & 65.10 & 0.86 \\
\hline Truk Ringan & 58 & 0 & 58 & 0.98 & 0.91 & 51.72 & 1.09 \\
\hline Truk Sedang & 58 & 0 & 58 & 0.98 & 0.91 & 51.72 & 1.09 \\
\hline Truk Berat & 58 & 0 & 58 & 0.98 & 0.91 & 51.72 & 1.09 \\
\hline
\end{tabular}


Tabel 3 Penghematan Waktu Tempuh

\begin{tabular}{cccc}
\hline $\begin{array}{c}\text { Jenis } \\
\text { Kendaraan }\end{array}$ & $\begin{array}{c}\text { Sebelum } \\
\text { Penanganan }\end{array}$ & $\begin{array}{c}\text { Setelah } \\
\text { Penanganan }\end{array}$ & $\begin{array}{c}\text { Manfaat } \\
\text { Waktu }\end{array}$ \\
\hline \hline Sedan & 1.23 & 0.93 & 0.30 \\
Utiliti & 1.23 & 0.93 & 0.30 \\
Bus Kecil & 1.45 & 1.05 & 0.40 \\
Bus Besar & 1.20 & 0.86 & 0.34 \\
Truk Ringan & 1.55 & 1.09 & 0.46 \\
Truk Sedang & 1.55 & 1.09 & 0.46 \\
Truk Berat & 1.55 & 1.09 & 0.46 \\
\hline
\end{tabular}

Sumber : Data olah, 2016

Nilai waktu total penumpang untuk tiap jenis kendaraan diperoleh dari perkalian nilai waktu penumpang dengan jumlah penumpang rata-rata tiap kendaraan dan prosentase nilai ekonomi perjalanan penumpang seperti pada tabel 4

Tabel 4 Tabel Nilai Waktu Total Penumpang

\begin{tabular}{lcccc}
\hline Jenis Kendaraan & $\begin{array}{c}\text { Jumlah } \\
\text { Penumpang } \\
\text { Rata-rata } \\
\text { (Orang) }\end{array}$ & $\begin{array}{c}\text { Persentase Nilai } \\
\text { Ekonomi } \\
\text { Perjalanan }\end{array}$ & $\begin{array}{c}\text { Nilai Waktu } \\
\text { Penumpang } \\
\text { (Rp./Jam) }\end{array}$ & $\begin{array}{c}\text { Nilai Waktu Total } \\
\text { Penumpang } \\
\text { (Rp./Jam/Kend) }\end{array}$ \\
\hline \hline Sedan & 3.3 & 50 & 9824 & $9,125.90$ \\
Utiliti & 5 & 30 & 9824 & $8,296.27$ \\
Bus Kecil & 16.2 & 30 & 9824 & $26,879.93$ \\
Bus Besar & 36.4 & 30 & 9824 & $60,396.88$ \\
Truk Ringan & 2 & 70 & 9824 & $7,743.19$ \\
Truk Sedang & 2 & 70 & 9824 & $7,743.19$ \\
Truk Berat & 2 & 70 & 9824 & $7,743.19$ \\
\hline
\end{tabular}

Sumber : Data olah, 2016

Tabel 5 Manfaat Nilai Waktu

\begin{tabular}{lrrrr}
\hline \multirow{2}{*}{ Jenis Kendaraan } & \multicolumn{2}{c}{$\begin{array}{c}\text { Nilai Waktu Total } \\
\text { (Rp./Kend/Jam) }\end{array}$} & $\begin{array}{c}\text { Penghematan } \\
\text { Waktu } \\
\text { Tempuh (Jam) }\end{array}$ & $\begin{array}{c}\text { Manfaat Nilai } \\
\text { Waktu Total } \\
\text { (Rp./Kend) }\end{array}$ \\
\cline { 2 - 3 } Peumpang & Komoditas & -1250 & $2,715.24$ \\
Sedan & $9,125.90$ & - & 0.30 & $2,468.40$ \\
Utiliti & $8,296.27$ & - & 0.40 & $10,722.13$ \\
Bus Kecil & $26,879.93$ & - & 0.34 & $20,553.99$ \\
Bus Besar & $60,396.88$ & 98,718 & 0.46 & $48,676.74$ \\
Truk Ringan & $7,743.19$ & 370,192 & 0.46 & $172,801.71$ \\
Truk Sedang & $7,743.19$ & 740,385 & 0.46 & $342,063.04$ \\
Truk Berat & $7,743.19$ & & & $\mathbf{6 0 0 , 0 0 1 . 2 4}$ \\
\hline Total & &
\end{tabular}


Biaya Investasi

Untuk melihat Investasi pembangunan Jalan Simpang Rukis Tanjung Kemuning meliputi biaya konstruksi yang terdiri dari biaya pembangunan jalan dan biaya pembebasan lahan, biaya holding dan biaya pemeliharaan.

Tabel 6 Biaya Investasi (dalam jutaan rupiah)

\begin{tabular}{crrrr}
\hline Tahun & Konstruksi & Holding & Pemeliharaan & \multicolumn{1}{c}{ Jumlah } \\
\hline \hline 2015 & 317,700 & - & - & 317,700 \\
2016 & - & - & - & - \\
2017 & - & - & - & - \\
2018 & - & 2,051 & 3,643 & 7,787 \\
2019 & - & 2,277 & 4,043 & 9,595 \\
2020 & - & 2,528 & 4,488 & 11,822 \\
\hline \hline TOTAL & & & & $\mathbf{3 4 6 , 9 0 4}$
\end{tabular}

Sumber : Kementerian PU-Pera, 2015

\section{Penghematan Biaya Operasi \\ Kendaraan (BOK) \\ Biaya Tetap}

Biaya tetap yang dihitung dalam analisis ini meliputi beberapa biaya antaranya :

1. Biaya Depresiasi,

2. Biaya Upah Awak Kendaraan,

3. Biaya Overhead.
Biaya Asuransi

Biaya asuransi masing-masing kendaraan dihitung dengan menggunakan Persamaan 2.5 sampai dengan Persamaan 2.9

Hasil perhitungan biaya asuransi pada Ruas Simpang Rukis - Tanjung Kemuning sebelum dan sesudah adanya penanganan, dapat dilihat pada table 7

Tabel 7 Manfaat Asuransi

\begin{tabular}{lccr}
\hline \multirow{2}{*}{ Jenis Kendaraan } & Biaya Asuransi (Rp./Kend) & \multicolumn{2}{c}{$\begin{array}{c}\text { Manfaat Asuransi per 1000 } \\
\text { km } \\
\text { (Rp. Kend) }\end{array}$} \\
\cline { 2 - 3 } & Sebelum & Sesudah & 117.36 \\
\hline Sedan & 483.37 & 366.01 & 117.36 \\
Utiliti & 483.37 & 366.01 & 51.83 \\
Bus Kecil & 188.49 & 136.65 & 142.25 \\
Bus Besar & 503.53 & 361.28 & 109.49 \\
Truk Ringan & 370.01 & 260.52 & 88.21 \\
Truk Sedang & 298.11 & 209.89 & 145.20 \\
Truk Berat & 490.69 & 345.48 & $\mathbf{7 7 1 . 7 1}$ \\
\hline TOTAL & & & \\
\hline
\end{tabular}

Sumber : Data olah, 2016

Dari perhitungan biaya asuransi di atas didapatkan manfaat asuransi per $1000 \mathrm{~km}$ sebesar Rp. 771.17,-. 


\section{Biaya Overhead}

Tabel 8 Biaya Overhead sebelum Adanya Penanganan

\begin{tabular}{lcccr}
\hline Jenis Kendaraan & $\begin{array}{c}\text { Biaya } \\
\text { Depresiasi }\end{array}$ & $\begin{array}{c}\text { Biaya Upah } \\
\text { Awak } \\
\text { Kendaraan }\end{array}$ & $\begin{array}{c}\text { Biaya } \\
\text { Asuransi }\end{array}$ & Biaya Overhead \\
\hline \multicolumn{1}{c}{$\mathrm{a}$} & $\mathrm{b}$ & $\mathrm{c}$ & $\mathrm{d}$ & $\mathrm{e}=0.20(\mathrm{~b}+\mathrm{c}+\mathrm{d})$ \\
\hline \hline Sedan & $9,461.66$ & $37,467.50$ & 483.37 & $9,482.51$ \\
Utiliti & $11,277.36$ & $37,467.50$ & 483.37 & $9,845.65$ \\
Bus Kecil & $11,688.20$ & $81,337.25$ & 188.49 & $18,642.79$ \\
Bus Besar & $37,795.36$ & $67,551.27$ & 503.53 & $21,170.03$ \\
Truk Ringan & $13,269.40$ & $141,975.98$ & 370.01 & $31,123.08$ \\
Truk Sedang & $13,913.98$ & $141,975.98$ & 298.11 & $31,237.61$ \\
Truk Berat & $24,805.11$ & $141,975.98$ & 490.69 & $33,454.36$ \\
\hline TOTAL & $\mathbf{1 2 2 , 2 1 1 . 0 8}$ & $\mathbf{6 4 9 , 7 5 1 . 4 6}$ & $\mathbf{2 , 8 1 7 . 5 7}$ & $\mathbf{1 5 4 , 9 5 6 . 0 2}$ \\
\hline Sumber $:$ Data & & & &
\end{tabular}

Sumber : Data olah, 2016

Tabel 9 Biaya Overhead setelah Adanya Penanganan

\begin{tabular}{lrrrr}
\hline $\begin{array}{c}\text { Jenis } \\
\text { Kendaraan }\end{array}$ & Biaya Depresiasi & $\begin{array}{c}\text { Biaya Upah } \\
\text { Awak } \\
\text { Kendaraan }\end{array}$ & $\begin{array}{c}\text { Biaya } \\
\text { Asuransi }\end{array}$ & Biaya Overhead \\
\hline \multicolumn{1}{c}{ a } & \multicolumn{1}{c}{$\mathrm{b}$} & $\mathrm{c}$ & $\mathrm{d}$ & $\mathrm{e}=0.20(\mathrm{~b}+\mathrm{c}+\mathrm{d})$ \\
\hline \hline Sedan & $7,164.40$ & $28,370.50$ & 366.01 & $7,180.18$ \\
Utiliti & $8,539.25$ & $28,370.50$ & 366.01 & $7,455.15$ \\
Bus Kecil & $8,473.95$ & $58,969.50$ & 136.65 & $13,516.02$ \\
Bus Besar & $27,118.20$ & $48,468.09$ & 361.28 & $15,189.51$ \\
Truk Ringan & $9,342.74$ & $99,962.68$ & 260.52 & $21,913.19$ \\
Truk Sedang & $9,796.58$ & $99,962.68$ & 209.89 & $21,993.83$ \\
Truk Berat & $17,464.82$ & $99,962.68$ & 345.48 & $23,554.60$ \\
TOTAL & $\mathbf{8 7 , 8 9 9 . 9 4}$ & $\mathbf{4 6 4 , 0 6 6 . 6 3}$ & $\mathbf{2 , 0 4 5 . 8 5}$ & $\mathbf{1 1 0 , 8 0 2 . 4 8}$ \\
\hline
\end{tabular}

Sumber : Data olah, 2016

\section{Total Manfaat Tetap}

Total manfaat tetap dihitung dari rekapitulasi dari manfaat depresiasi, upah awak kendaraan, asuransi dan biaya overhead sebelum dan sesudah adanya penanganan ruas Simpang rukis - Tanjung Kemuning yang disajikan pada tabel 10 dan tabel 11

Tabel 10 Biaya Tetap sebelum Penanganan

\begin{tabular}{lcccrc}
\hline $\begin{array}{c}\text { Jenis } \\
\text { Kendaraan }\end{array}$ & $\begin{array}{c}\text { Biaya } \\
\text { Depresiasi }\end{array}$ & $\begin{array}{c}\text { Biaya Upah } \\
\text { Awak } \\
\text { Kendaraan }\end{array}$ & $\begin{array}{c}\text { Biaya } \\
\text { Asuransi }\end{array}$ & $\begin{array}{c}\text { Biaya } \\
\text { Overhead }\end{array}$ & Biaya Tetap \\
\hline \multicolumn{1}{c}{$\mathrm{a}$} & $\mathrm{b}$ & $\mathrm{c}$ & $\mathrm{d}$ & $\begin{array}{c}\mathrm{e}=0.20 \\
(\mathrm{~b}+\mathrm{c}+\mathrm{d})\end{array}$ & $\mathrm{f}=\mathrm{b}+\mathrm{c}+\mathrm{d}+\mathrm{e}$ \\
\hline \hline Sedan & $9,461.66$ & $37,467.50$ & 483.37 & $9,482.51$ & $104,328.43$ \\
Utiliti & $11,277.36$ & $37,467.50$ & 483.37 & $9,845.65$ & $106,870.41$ \\
Bus Kecil & $11,688.20$ & $81,337.25$ & 188.49 & $18,642.79$ & $212,025.24$ \\
Bus Besar & $37,795.36$ & $67,551.27$ & 503.53 & $21,170.03$ & $216,245.03$
\end{tabular}




\begin{tabular}{lrrrrr} 
Truk Ringan & $13,269.40$ & $141,975.98$ & 370.01 & $31,123.08$ & $360,207.54$ \\
Truk Sedang & $13,913.98$ & $141,975.98$ & 298.11 & $31,237.61$ & $360,937.37$ \\
Truk Berat & $24,805.11$ & $141,975.98$ & 490.69 & $33,454.36$ & $376,647.16$ \\
\hline TOTAL & $\mathbf{1 2 2 , 2 1 1 . 0 8}$ & $\mathbf{6 4 9 , 7 5 1 . 4 6}$ & $\mathbf{2 , 8 1 7 . 5 7}$ & $\mathbf{1 5 4 , 9 5 6 . 0 2}$ & $\mathbf{1 , 7 3 7 , 2 6 1 . 1 9}$ \\
\hline
\end{tabular}

Sumber : Data olah, 2016

Tabel 11 Biaya Tetap setelah Penanganan

\begin{tabular}{lcccrr}
\hline $\begin{array}{c}\text { Jenis } \\
\text { Kendaraan }\end{array}$ & $\begin{array}{c}\text { Biaya } \\
\text { Depresiasi }\end{array}$ & $\begin{array}{c}\text { Biaya Upah Awak } \\
\text { Kendaraan }\end{array}$ & $\begin{array}{c}\text { Biaya } \\
\text { Asuransi }\end{array}$ & $\begin{array}{c}\text { Biaya } \\
\text { Overhead }\end{array}$ & Biaya Tetap \\
\hline \multicolumn{1}{c}{$\mathrm{a}$} & $\mathrm{b}$ & $\mathrm{c}$ & $\mathrm{d}$ & $\begin{array}{c}\mathrm{e}=0.20 \\
(\mathrm{~b}+\mathrm{c}+\mathrm{d})\end{array}$ & $\mathrm{f}=\mathrm{a}+\mathrm{b}+\mathrm{c}+\mathrm{d}$ \\
\hline \hline Sedan & $7,164.40$ & $28,370.50$ & 366.01 & $7,180.18$ & $43,081.09$ \\
Utiliti & $8,539.25$ & $28,370.50$ & 366.01 & $7,455.15$ & $44,730.92$ \\
Bus Kecil & $8,473.95$ & $58,969.50$ & 136.65 & $13,516.02$ & $81,096.12$ \\
Bus Besar & $27,118.20$ & $48,468.09$ & 361.28 & $15,189.51$ & $91,137.08$ \\
Truk Ringan & $9,342.74$ & $99,962.68$ & 260.52 & $21,913.19$ & $131,479.13$ \\
Truk Sedang & $9,796.58$ & $99,962.68$ & 209.89 & $21,993.83$ & $131,962.98$ \\
Truk Berat & $17,464.82$ & $99,962.68$ & 345.48 & $23,554.60$ & $141,327.58$ \\
\hline TOTAL & $\mathbf{8 7 , 8 9 9 . 9 4}$ & $\mathbf{4 6 4 , 0 6 6 . 6 3}$ & $\mathbf{2 , 0 4 5 . 8 5}$ & $\mathbf{1 1 0 , 8 0 2 . 4 8}$ & $\mathbf{6 6 4 , 8 1 4 . 9 0}$ \\
\hline
\end{tabular}

Sumber: Data olah, 2016

\section{Biaya Tidak Tetap}

Biaya tidak tetap terdiri dari biaya komsumsi bahan bakar, biaya komsumsi oli, biaya konsumsi suku cadang, biaya konsumsi suku cadang, biaya upah tenaga pemeliharaan,dan biaya konsumsi ban. Biaya-biaya tersebut dalam satu rupiah perKilometer yang besarnya bergantung pada pengguna kendaraan. Data kondisi jalan sebelum dan sesudah pananganan disajikan pada tabel 12 berikut ini.

Tabel 12 Data Kondisi Jalan sebelum dan sesudah Penanganan

\begin{tabular}{|c|c|c|c|}
\hline No. & Kondisi Jalan & Sebelum & Sesudah \\
\hline 1. & Ruas Jalan & \multicolumn{2}{|c|}{ Simpang Rukis - Tanjung Kemuning } \\
\hline 2. & Nomor Ruas & \multicolumn{2}{|c|}{021} \\
\hline 3. & Panjang Ruas & \multicolumn{2}{|c|}{$56.27 \mathrm{KM}$} \\
\hline 4. & Lebar Jalan & 6.00 & 7.00 \\
\hline 5. & Lebar Bahu & 1.00 & 2.00 \\
\hline 6. & Kondisi Medan & Bukit & Datar \\
\hline 7. & Hambatan Samping & Medium & Medium \\
\hline 8. & Tanjakan Rata-rata $\left(\mathrm{R}_{\mathrm{R}}\right)$ & 12.5 & 2.5 \\
\hline 9. & Turunan Rata-rata $\left(\mathrm{F}_{\mathrm{R}}\right)$ & -12.5 & -2.5 \\
\hline 10. & Tanjakan dan Turunan $\left(\mathrm{T}_{\mathrm{TR}}\right)$ & 12.5 & 2.5 \\
\hline 11. & Derajat Tikungan $\left(\mathrm{D}_{\mathrm{TR}}\right)$ & 15 & 15 \\
\hline 12. & Kekasaran (IRI) & 8 & 2 \\
\hline & Volume Jam Sibuk & 3189 & 3189 \\
\hline 14. & Volume Jam Sibuk (V) & 2233 & 2233 \\
\hline 15. & Kapasitas Jalan ( C ) & 2304 & 2821 \\
\hline
\end{tabular}




\begin{tabular}{clcc}
\hline No. & \multicolumn{1}{c}{ Kondisi Jalan } & Sebelum & Sesudah \\
\hline 16. & Volume per Kapasitas $(\mathrm{V} / \mathrm{C})$ & 0.97 & 0.79 \\
\hline 17. & Kecepatan Rata-rata $(\mathrm{VR})$ & 51.46 & 60.64 \\
\hline 18. & Percepatan Rata-rata $\left(\mathrm{A}_{\mathrm{R}}\right)$ & 0.0124 & 0.0101 \\
\hline 19. & Simpangan Baku Percepatan $\left(\mathrm{S}_{\mathrm{AR}}\right)$ & 0.3846 & 0.5296 \\
\hline
\end{tabular}

Sumber : Data olah, 2016

\section{Total Manfaat Tidak Tetap}

Manfaat tidak tetap Jalan Simpang Rukis - Tanjung Kemuning meliputi penjumlahan dari manfaat penghematan biaya konsumsi bahan bakar, manfaat penghematan biaya konsumsi oli, manfaat penghematan biaya suku cadang, manfaat biaya upah tenaga pemeliharaan,dan manfaat biaya konsumsi ban.

Manfaat tidak tetap untuk Jalan Simpang Rukis - Tanjung Kemuning dan manfaat biaya tidak dapat dilihat pada tabel 13 di bawah ini :

Tabel 13 Manfaat Biaya Tidak Tetap

\begin{tabular}{lrrrrrr}
\hline $\begin{array}{c}\text { Jenis } \\
\text { Kendaraan }\end{array}$ & Bi BBM & \multicolumn{1}{c}{ BO $\mathbf{i}$} & BP $\mathbf{i}$ & BU i & BB i & TOTAL \\
\hline \hline Sedan & 93.18 & 1.81 & 320.94 & 185.22 & 103.46 & 704.60 \\
Utiliti & 148.89 & 2.89 & 320.94 & 185.22 & 103.46 & 761.39 \\
Bus Kecil & 117.79 & 3.05 & 248.20 & 582.59 & 181.46 & $1,133.08$ \\
Bus Besar & 636.25 & 31.41 & 367.47 & 355.57 & 3.51 & $1,394.21$ \\
Truk Ringan & 113.68 & 2.81 & 133.42 & 396.12 & 462.27 & $1,108.29$ \\
Truk Sedang & 121.62 & 6.00 & 393.57 & 704.16 & 5.43 & $1,230.78$ \\
Truk Berat & $1,137.51$ & 112.31 & 113.20 & 352.54 & 9.10 & $1,724.66$ \\
\hline \hline$\quad$ Total & $\mathbf{2 , 3 6 8 . 9 3}$ & $\mathbf{1 6 0 . 2 7}$ & $\mathbf{1 , 8 9 7 . 7 2}$ & $\mathbf{2 , 7 6 1 . 4 2}$ & $\mathbf{8 6 8 . 6 7}$ & $\mathbf{8 , 0 5 7 . 0 1}$ \\
\hline \multicolumn{1}{c}{ Manfaat } & & & & &
\end{tabular}

Dari Tabel 13 di atas didapatkan nilai manfaat tidak tetap untuk ruas jalan Simpang Rukis - Tanjung Kemuning adalah Rp. 8.057,01

\section{Dampak ekonomi dilihat dari penghematan waktu}

Dari hasil hitungan dapat disimpulkan bahwa waktu untuk
Simpang Rukis - Tanjung Kemuning atau sebaliknya sebelum ada pembangunan untuk melintasi jalan ini sepanjang dari Simpang Rukis Tanjung Kemuning sepanjang 56,27 $\mathrm{Km}$ diapatkan penghematan waktu tempuh seperti pada Tabel 11 dan kecepatan tempuh rata-rata disajikan pada

Tabel 
Tabel 14 Kecepatan Tempuh Rata-rata

\begin{tabular}{|c|c|c|}
\hline Jenis Kendaraan & $\begin{array}{l}\text { Sebelum } \\
\text { Penanganan } \\
\text { (km/jam) }\end{array}$ & $\begin{array}{l}\text { Setelah Penanganan } \\
\text { (km/jam) }\end{array}$ \\
\hline Sedan & 45.92 & 60.64 \\
\hline Utiliti & 45.92 & 60.64 \\
\hline Bus Kecil & 38.79 & 53.51 \\
\hline Bus Besar & 46.71 & 65.10 \\
\hline Truk Ringan & 36.42 & 51.72 \\
\hline Truk Sedang & 36.42 & 51.72 \\
\hline Truk Berat & 36.42 & 51.72 \\
\hline $\begin{array}{l}\text { Sumber : Data olah, } 2016 \\
\text { ak ekonomi dilihat } \\
\text { ungan. } \\
\text { Resarnva }\end{array}$ & & $\begin{array}{l}\text { Simpang Rukis - } \\
\text { Kemuning } \\
\text { dinyatakan layak } \\
\text { ekonomi }\end{array}$ \\
\hline
\end{tabular}

\section{Dampak ekonomi dilihat dari besar keuntungan.}

Kendaraan sebelum adanya penanganan jalan Simpang Rukis Tanjung Kemuning adalah Rp. 3.932.430,06/kendaraan dan Biaya Operasi Kendaraan setelah adanya penanganan jalan sebesar Rp. 2.792.298,97/kendaraan.

Sehingga besarnya keuntungan BOK dihitung dari selisih keuntungan BOK sebelum dan sesudah adanya penanganan yaitu Rp. 3.932.430,06 Rp. $2.792 .298,97=$ Rp. 1.140.131.09.

Dampak ekonomi dilihat dari perhitungan Net Present Value (NPV) dan Benafit Cost Rasio (BCR)

Hasil Perhitungan untuk Net Present Value (NPV) dapat dilihat sebagai berikut untuk 5 (lima) tahun kedepan tahun 2020 adalah sebagai berikut :

$\mathrm{NPV}=$ Dari Persamaan 2.34 maka NPV merupakan selisih antara total Present Value (PV) manfaat dan total Present Value $(\mathrm{PV})$ biaya $=$ Rp 1.921.187.

Nilai Sekarang Bersih (Net Present Value/NPV) Rp 1.921.187,$>0$. Pembangunan Jalan
Hasil Perhitungan untuk Benafit Cost Rasio (BCR) dapat dilihat sebagai berikut untuk 5 (lima) tahun kedepan tahun 2020 adalah sebagai berikut :
BCR = Diperoleh dengan membandingkan nilai Present Value (PV) manfaat dengan PV biaya.

$\mathrm{BCR}=$ Dari Persamaan 2.35 Besaran total dari komponen manfaat pada tahun ke $\mathrm{n}$ Present Value (PV) manfaat) / Besaran total dari komponen biaya pada tahun ke n Present Value (PV) biaya)

Nilai Manfaat Biaya (Benefit Cost Ratio, BCR) Nilai BCR 1,18 > 1 . Pembangunan Jalan Simpang Rukis Tanjung Kemuning tersebut dinyatakan layak dilaksanakan secara ekonomi.

\section{Analisis Sensitivitas}

Analisis sensitivitas kelayakan investasi dengan mengubah nilai suatu variabel dan mengamati pengaruhnya terhadap kelayakan investasi.

Hasil analisis sensitivitas dapat dilihat pada tabel 14. Dari Tabel tersebut dapat dilihat bahwa : 
1. Pada saat biaya naik $15 \%$ dan nilai manfaat tetap, NPV bernilai Rp. 1.921.187,- > 0 dan nilai BCR $1.03>1$

2. Pada saat biaya tetap dan nilai manfaat turun $15 \%$, nilai NPV turun menjadi Rp. 1.306.921.187,$>0$ dan nilai $\mathrm{BCR}$ turun menjadi $1,004>1$

3. Pada saat biaya naik $15 \%$ dan nilai manfaat turun $15 \%$, nilai NPV turun menjadi Rp. 1.306.921.187,$>0$ dan nilai $\mathrm{BCR}$ turun menjadi $0,87<1$, maka pembangunan Jalan Simpang Rukis - Tanjung Kemuning tersebut dinyatakan tidak layak secara ekonomi

Dapat diartikan bahwa nilai BCR $=1,18$ pada saat manfaat dan biaya normal, sangat sensitif terhadap perubahan nilai manfaat dan atau biaya.

Pengembangan Ruas Jalan Simpang Rukis - Tanjung Kemuning sangat strategis dalam rangka pengembangan perekonomian baik antara Provinsi maupun antar daerah yang berpotensi dan tingkat pertumbuhan perekonomian yang tinggi, karena jalur jalan ini merupakan jalan lintas barat yang dilalui tarnsportasi yang membawa hasil-hasil produksi dari bagian kota Bengkulu dan sekitarnya ke Provinsi Lampung akan lebih mudah menuju oulet/pelabuhan dalam kota yang perkembagannya semakin maju.

Pembangunan Ruas Jalan Simpang Rukis - Tanjung Kemuning ini juga bisa membuka daerah-daerah yang terisolir yang mempunyai potensi dan peluang untuk berkembang. Jalur Simpang Rukis - Tanjung Kemuning merupakan jalur jalan lintas barat dan merupakan jalur urat nadi perekonomian Propinsi Bengkulu dengan kondisi jalan yang sempurna dan mantap dapat juga mencerminkan sistem pemerintahan Propinsi Bengkulu (Tamin, 2007).

\section{PENUTUP \\ Kesimpulan}

Berdasarkan hasil penelitian, maka 1) terjadinya penghematan waktu, 2) terjadinya pengurangan biaya kendaraan. Dengan adanya pembangunan dan pemeliharaan jalan dan jembatan Simpang Rukis Tanjung Kemuning diharapkan laju transportasi yang efisien dan ekonomis sehingga dapat mempercepat perekonomian propinsi Bengkulu khususnya masyarakat Simpang Rukis - Tanjung Kemuning.

\section{Saran}

Berdasarkan hasil analisis dan kesimpulan, maka terdapat beberapa saran yang terkait dengan pembangunan jalan Simpang Rukis Tanjung Kemuning antara lain :

1. Perlunya survey lalu lintas per tahunnya untuk mendapatkan data pertumbuhan lalu lintas yang riil untuk mendapatkan data primer yang lebih nyata, sehingga hasil analisis menjadi lebih baik dan sempurna.

2. Perlunya kajian lebih lanjut untuk mengetahuhi manfaat sosial (Social Benefit) yang akan diperoleh masyarakat berupa perkembangan ekonomi masyarakat sekitar daerah Pembangunan jalan Simpang Rukis - Tanjung Kemuning.

3. Pemerintahan Propinsi Bengkulu perlu melakukan pengaturan kembali terhadap tata guna lahan, untuk membenahi ruang manfaat jalan, ruang jalan, dan ruang pengawasan jalan, yang berada di sepanjang jalan koridor ruas jalan untuk mendukung kelancaran 
pelaksanaan pada masa yang akan datang.

\section{DAFTAR PUSTAKA}

Badan Pusat Statistik. (2015), Propinsi Bengkulu Dalam Angka 2014, Propinsi Bengkulu.

Depertemen Pekerjaan Umum. (2005), Perhitungan Biaya Operasi Kendaraan: Bagian 1 Biaya Biaya Tidak Tetap (Running Cost), Pedoman Bahan KonstruksiBangunan dan Rekayasa Sipil, Jakarta.

Departemen Pekerjaan Umum. (2015), Pedoman Perhitungan Biaya Operasi Kendaraan, Nomor : Pd.T-15-2005-B, Puslitbang Prasarana Transportasi, Jakarta.

Hensher, D.A, Banard, P.O,, Milthorpe, F.W and Smith, N.C. (1990), Urban Tolled Roads and the Value of Business, University of Sydney, Australia.
Husnan S., Suwarsono. (1999), Studi Kelayakan Proyek,(Edisi ketiga),UPP AMP YKPN, Yogyakarta.

Pemerintah Republik Indonesia. (2004), Undang-Undang Nomor 38 Tahun 2004, tentang Jalan, Jakarta.

Pusat Penelitian dan Pengembangan Prasarana Transportasi. (2005), Model Perhitungan Biaya Operasi Kendaraan (BOK) dan Pedoman Analisis Ekonomi Pembangunan Jalan, Laporan Akhir Penelitian, Departemen Pekerjaan Umum, Bandung.

Pudjosumarto, M. (1998), Evaluasi Proyek, (Edisi Kedua), Liberty, Yogyakarta.

Tamin, O.Z. (2007), Perencanaan dan Permodelan Transportasi, (Edisi Kedua), ITB,Bandung. 